\title{
Analysis of well and layer selection method for fracturing displacement in thin-and-poor layers in the transition zone of $A$ Oilfield
}

\author{
Yanhong Pan* \\ Dynamic room of Geological Research Institute of the fifth oil production plant of Daqing Oilfield China
}

\begin{abstract}
This paper mainly provides the well and layer selection method of fracturing displacement. It mainly solves the problem of insufficient formation energy and lack of forming effective communication between oil and water wells, resulting in poor water injection capacity in thin-and-poor layers, poor oil well production capacity, formation deficit and poor seepage capacity. The research includes the following two parts. (1) Target wells were optimized by selecting those with relatively perfect injection production relationship, poor oil-water well connectivity and long-term formation deficit. The water injection wells should be those with porosity, low air permeability and some development potential. They are required to meet the construction requirements of large capability of fracturing fluid injection into water wells. (2) Target layers were optimized based on the selection of the injection-production relationship of the target well, reservoir development thickness, interlayer thickness, liquid production, liquid production intensity, formation pressure, production situation and other parameters. Then, the sedimentary unit with poor production and high potential is selected as the target layer. This method improves the effect of stimulation and development in thin-and-poor layers.
\end{abstract}

Key words: Transition zone; fracturing oil displacement; well and layer selection.

\section{Background}

At present, the conventional selection for well and layer fracturing mainly focuses on the well layers with pollution whose reservoir seepage requires improvement. It improves oil production by changing the seepage conditions of the formation within a small domain, removing reservoir pollution and improving reservoir seepage capacity. However, the fracturing oil displacement technology mainly selects thin-and-poor layers, energy deficit layers and poor seepage layers. Large-scale oil displacement fluid was injected into the water injection well to supplement the formation energy. The seepage capacity was improved between the oil production well and the water injection well within a large domain. Then, the water injection well and the oil production well with a spacing of $200 \mathrm{~m}$ or more can be effectively connected. Therefore, the conventional fracturing well and layer selection method is not suitable for fracturing oil displacement technology.

\section{Technical methods}

\subsection{Optimization of target wells}

We select the wells of relatively complete injectionproduction relationship, poor oil-water well connectivity and long-term formation deficit. The water injection wells of the selected well group shall be those with low porosity, low air permeability, an average porosity range of $17-25 \%$ and air permeability of $20-30 \mathrm{md}$, poor or no water absorption for a long time, and the injection production well spacing range of $150-300 \mathrm{~m}$. In addition, they should be with large spacing between injection production wells, poor production of the well group, enrichment of remaining oil and certain potential for tapping. The operational requirements of pressure fracturing for water injection wells should be met considering the ground condition, cementing quality and casing damage.

\footnotetext{
* Corresponding author: 123988345@qq.Com
} 


\subsection{Optimization the target layer of the target well}

Parameters were optimized on the selected wells including injection production relationship, reservoir development thickness, interlayer thickness, liquid production, liquid production intensity, formation pressure, production situation, geological reserves of single sand layer, water cut level, recovery degree. The target layers are those sedimentary units with poor production and high potential. The calculation of formation deficit was completed by the balanced injection-production ratio method. The five-point water injection method is taken as an example, as shown in Figure 1.

$$
\begin{aligned}
& Q_{1}=Q_{a} h_{2} /\left(h_{1}+h_{2}+h_{3}+h_{4}\right) \\
& Q_{2}=Q_{b} h_{5} /\left(h_{5}+h_{6}+h_{7}+h_{8}\right) \\
& Q_{3}=Q_{c} h_{9} /\left(h_{9}+h_{10}+h_{11}+h_{12}\right) \\
& Q_{4}=Q_{d} h_{13} /\left(h_{13}+h_{14}+h_{15}+h_{16}\right)
\end{aligned}
$$

Where $\mathrm{H} 1, \mathrm{H} 2, \mathrm{H} 3, \ldots$ and $\mathrm{H} 16$ are the connecting thickness between oil and water well; a, b, c and d are the four oil wells; $Q_{a}, Q_{b}, Q_{c}$ and $Q_{d}$ are the cumulative liquid production of corresponding oil wells; $Q_{1}, Q_{2}$, $Q_{3}$ and $Q_{4}$ are the amount of liquid provided by well a to corresponding oil wells. The cumulative injection liquid is calculated as follows.

$$
Q=Q_{1}+Q_{2}+Q_{3}+Q_{4}
$$

The cumulative injection volume of well a is $P$. If

$$
Q>P \text {, the formation is in deficit. }
$$

Specifically, the well group is comprised of an oil well which is connected to four water wells. The number ratio of oil and water wells is 1:1. The water well A provides water to surrounding oil wells a, b, c and d. The oil well a is supplied with water from the well $\mathrm{A}$ and its liquid production becomes $Q_{1}=Q_{a} h_{2} /\left(h_{1}+h_{2}+h_{3}+h_{4}\right)$ where the proportion of liquid production equals the connection thickness between wells a and A divided by the thickness between the well a and its surrounding connected water wells. Similarly, the water supply of oil well b from well A becomes $Q_{2}=Q_{b} h_{5} /\left(h_{5}+h_{6}+h_{7}+h_{8}\right)$, where the proportion of liquid production equals the connection thickness between wells $b$ and A divided by the thickness between the well $b$ and its surrounding connected water wells. For the oil well c, its water supply from well A becomes $Q_{3}=Q_{c} h_{9} /\left(h_{9}+h_{10}+h_{11}+h_{12}\right)$, where the proportion of liquid production equals the connection thickness between wells $\mathrm{c}$ and A divided by the thickness between the well $\mathrm{c}$ and its surrounding connected water wells. For the oil well d, its water supply from well A becomes $Q_{4}=Q_{d} h_{13} /\left(h_{13}+h_{14}+h_{15}+h_{16}\right)$, where the proportion of liquid production equals the connection thickness between wells $d$ and A divided by the thickness between the well $\mathrm{d}$ and its surrounding connected water wells. For the water injection well A, the sum of the cumulative liquid production of its four surrounding oil wells is $Q=Q_{1}+Q_{2}+Q_{3}+Q_{4}$. If the cumulative water injection from the water well $\mathrm{A}$ is less than the liquid production from its four surrounding oil wells due to water injection, it confirms that the formation is in deficit. This method of calculating the formation deficit is referred to be as the balanced injection-production ratio method.

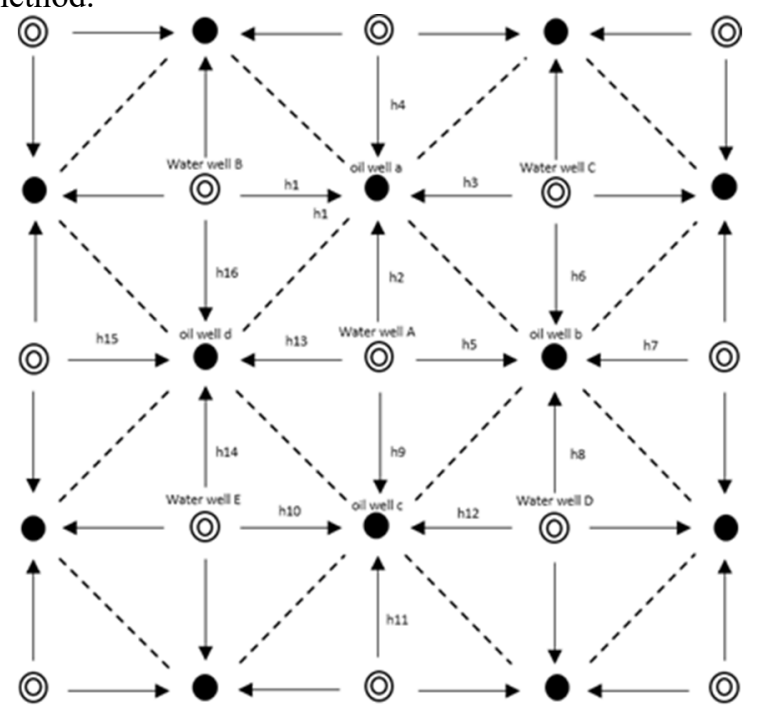

Fig. 1 Schematic of water injection by the five-point method It guarantees the requirements for improving the overall development effect of the well group. Because the connectivity of thin-and-poor layers of selected wells are improved, the recovery degree of thin layers of connected wells are increased. For the water wells, the injection capacity is greatly improved following the field operations. This improves the water absorption in thinand-poor layers and the degree of water drive control is improved.

\section{Field Cases}

Within the selected wells, parameters were considered for optimization which included injection production relationship, reservoir development thickness, interlayer thickness, liquid production, liquid production intensity, formation pressure, production situation, geological reserves of single sand layer, water cut level, recovery degree. The results are that 13 sedimentary units with poor production and high potential are selected as the target layers, such as CII11, CII12, CII13, CII41, CII42, CII50, CII92, CII100, CII111, CII112, CII114, CII115 and CII120.

The geological reserves of single sand-layer of well A-10XIE 117 are calculated as follows. The well c-10- XIE 117 was injected in July 2012, where 29 sedimentary units were shot. The sandstone of CII formation was shot with $17.5 \mathrm{~m}$ length and the effective thickness is $3.9 \mathrm{~m}$ and geological reserves reaches 13298 tons. The geological reserves of single sand-layer are calculated according to the geological reserves, sand body characteristics, single sand-layer thickness, reservoir physical properties and 
other parameters. Table 1 shows the geological reserve of each interval of the well.

Finally, according to the parameters such as interlayer thickness, production situation and reservoir physical properties, the target layers are divided to specific intervals according to the principle of similar production situation and reservoir physical properties. It is divided into 4 fracturing intervals. The thickness of fractured sandstone is $11.8 \mathrm{~m}$ and the effective thickness is $3.3 \mathrm{~m}$. Table 2 shows the division of each interval of the well.

Table 1 The geological reserves of each interval of the well A10-XIE 117

\begin{tabular}{|c|c|c|c|c|c|c|}
\hline \multirow{2}{*}{$\begin{array}{c}\text { Layer } \\
\#\end{array}$} & \multicolumn{3}{|c|}{ Thickness (m) } & \multirow{2}{*}{$\begin{array}{c}\begin{array}{c}\text { Formation } \\
\text { pressure }\end{array} \\
(\mathrm{MPa})\end{array}$} & \multirow{2}{*}{$\begin{array}{c}\text { Geological } \\
\text { reserves } \\
(\mathrm{t})\end{array}$} & \multirow{2}{*}{$\begin{array}{c}\text { Recovery } \\
\text { degree } \\
(\%)\end{array}$} \\
\hline & $\begin{array}{l}\text { Interlayer } \\
\text { thickness }\end{array}$ & $\begin{array}{l}\text { Sandstone } \\
\text { thickness }\end{array}$ & $\begin{array}{l}\text { Effective } \\
\text { thickness }\end{array}$ & & & \\
\hline $\mathrm{CII1}_{1}$ & 1.6 & 0.6 & & 8.46 & 178 & 22.4 \\
\hline $\mathrm{CII}_{2}$ & 0.6 & 0.6 & & 8.34 & 178 & 21.4 \\
\hline $\mathrm{CII}_{3}$ & 4.8 & 0.5 & 0.3 & 8.33 & 409 & 50.5 \\
\hline $\mathrm{CII} 2_{0}$ & 2.2 & 0.8 & & 8.12 & 238 & 22.7 \\
\hline $\mathrm{CII}_{1}$ & 0.6 & 0.4 & & 8.34 & 162 & 25 \\
\hline $\mathrm{CII}_{2}$ & 0.8 & 0.6 & 0.6 & 8.39 & 315 & 8.1 \\
\hline $\mathrm{CII}_{3}$ & 4.4 & 0.6 & & 8.9 & 242 & 6.7 \\
\hline $\mathrm{CII}_{1}$ & 1.5 & 1.1 & & 8.65 & 1096 & 9 \\
\hline $\mathrm{CII}_{2}$ & 3.2 & 0.6 & & 8.5 & 178 & 10.3 \\
\hline CII50 & 4.2 & 2.3 & 1.4 & 8.57 & 3251 & 20.6 \\
\hline $\mathrm{CII}_{1}$ & 0.4 & 0.4 & & 8.53 & 197 & 10.3 \\
\hline $\mathrm{CII}_{2}$ & 1.1 & 0.5 & & 8.79 & 149 & 8.7 \\
\hline $\mathrm{CII}_{1}$ & 1.4 & 1.1 & & 8.77 & 327 & 6.3 \\
\hline $\mathrm{CII}_{2}$ & 0.6 & 0.8 & & 8.98 & 238 & 12.8 \\
\hline $\mathrm{CII9}_{1}$ & 2 & 0.5 & & 9.02 & 175 & 10 \\
\hline $\mathrm{CII9}_{2}$ & 4.8 & 0.8 & 0.4 & 8.61 & 1606 & 24 \\
\hline $\mathrm{CIII0}_{0}$ & 1.5 & 0.5 & & 8.94 & 149 & 2.7 \\
\hline $\mathrm{CII11}_{1}$ & 3.3 & 1.1 & & 8.98 & 1105 & 22.8 \\
\hline $\mathrm{CIII1}_{2}$ & 1.7 & 1.1 & 1.2 & 9.48 & 1606 & 4.2 \\
\hline $\mathrm{CII11}_{4}$ & 0.7 & 1.5 & & 9.93 & 1172 & 24 \\
\hline CII115 & 1.3 & 0.5 & & 9.64 & 149 & 5.6 \\
\hline $\mathrm{CIII2}_{0}$ & 60.1 & 0.6 & & 9.91 & 178 & 4.8 \\
\hline 合计 & & 17.5 & 3.9 & 8.83 & 13298 & 15.1 \\
\hline
\end{tabular}

Table 2 The division of each interval of the well A-10-XIE 117

\begin{tabular}{|c|c|c|c|c|c|c|}
\hline \multirow{2}{*}{$\begin{array}{c}\text { Sub- } \\
\text { layer } \\
\#\end{array}$} & \multicolumn{2}{|c|}{$\begin{array}{l}\text { Perforated interval } \\
(\mathrm{m})\end{array}$} & \multicolumn{3}{|c|}{ Thickness (m) } & \multirow{2}{*}{$\begin{array}{l}\text { Fracturing } \\
\text { stuck section }\end{array}$} \\
\hline & from & to & interlayer & Shoot & Effective & \\
\hline $\mathrm{CIII}_{1}$ & 1059.1 & 1058.5 & 1.6 & 0.6 & & \multirow{3}{*}{ 一 } \\
\hline $\mathrm{CII}_{2}$ & 1061.3 & 1060.7 & 0.6 & 0.6 & & \\
\hline $\mathrm{CII}_{3}$ & 1062.4 & 1061.9 & 4.8 & 0.5 & 0.3 & \\
\hline $\mathrm{CII} 2_{0}$ & 1068 & 1067.2 & 2.2 & 0.8 & & \\
\hline $\mathrm{CII}_{1}$ & 1070.6 & 1070.2 & 0.6 & 0.4 & & \\
\hline $\mathrm{CII}_{2}$ & 1071.8 & 1071.2 & 0.8 & 0.6 & 0.6 & \\
\hline $\mathrm{CII}_{3}$ & 1073.2 & 1072.6 & 4.4 & 0.6 & & \\
\hline $\mathrm{CII}_{1}$ & 1078.7 & 1077.6 & 1.5 & 1.1 & & \multirow{3}{*}{ 二 } \\
\hline $\mathrm{CII}_{2}$ & 1080.8 & 1080.2 & 3.2 & 0.6 & & \\
\hline $\mathrm{CII}_{0}$ & 1086.3 & 1084 & 4.2 & 2.3 & 1.4 & \\
\hline $\mathrm{CII}_{1}$ & 1090.9 & 1090.5 & 0.4 & 0.4 & & \\
\hline $\mathrm{CII}_{2}$ & 1091.8 & 1091.3 & 1.1 & 0.5 & & \\
\hline CII $8_{1}$ & 1094 & 1092.9 & 1.4 & 1.1 & & \\
\hline $\mathrm{CII}_{2}$ & 1096.2 & 1095.4 & 0.6 & 0.8 & & \\
\hline CII9 $9_{1}$ & 1097.3 & 1096.8 & 2 & 0.5 & & \\
\hline $\mathrm{CII} 9_{2}$ & 1100.1 & 1099.3 & 4.8 & 0.8 & 0.4 & \multirow{3}{*}{ 三 } \\
\hline $\mathrm{CIIIO}_{0}$ & 1105.4 & 1104.9 & 1.5 & 0.5 & & \\
\hline CII1 $11_{1}$ & 1108 & 1106.9 & 3.3 & 1.1 & & \\
\hline $\mathrm{CIII1}_{2}$ & 1112.4 & 1111.3 & 1.7 & 1.1 & 1.2 & \multirow{4}{*}{ 四 } \\
\hline $\mathrm{CII}_{11} 1_{4}$ & 1115.6 & 1114.1 & 0.7 & 1.5 & & \\
\hline CII115 & 1116.8 & 1116.3 & 1.3 & 0.5 & & \\
\hline CII12 $2_{0}$ & 1118.7 & 1118.1 & 60.1 & 0.6 & & \\
\hline
\end{tabular}

The technical operations were completed for the well A10-XIE 117 on November 17, 2017. A total of 10320 $631 \mathrm{~m} 3$ of oil displacement fluid was injected. After that, the pipe string could not be pulled out and required overhaul. This well was re-opened after the overhaul on March 15, 2018. The injection capacity was greatly improved. Up to now, the cumulative water increase is $43881 \mathrm{~m} 3$.
Four effective oil wells are connected to the well A-10XIE 117.The injection allocation was increased from $50 \mathrm{~m} 3$ to $65 \mathrm{~m} 3$ on May 3, 2018. On May 7, 2018, the water injection was temporarily increased to $80 \mathrm{~m} 3$.

After the implement of the selection of well and layer, large-scale oil displacement fluids were injected. The connection relationship was improved for the thin-andpoor layers between water-injection and production wells. The current connection distance is 3.5 times that of the original one. The water injection volume of the injection well is $79 \mathrm{~m} 3$ compared to zero. The injection pressure is reduced from $13 \mathrm{Mpa}$ to $10 \mathrm{MPa}$, and the average liquid production intensity of the oil well is increased from $1 \mathrm{t} /$ D.M to $6 t$ / D.M. The utilization degree of thin-and-poor layers was increased from $31 \%$ to $55 \%$. Up to October 31 , 2019, the functional period reached 922 days, with a cumulative increase of $1041 \mathrm{t}$.

\section{Conclusions}

This method can effectively select the well layers with long-term formation deficit and poor connection between production and water-injection wells. The connecting distance between the production and water-injection wells is more than 3 times of the original connecting distance, which greatly improves the seepage capacity of the fluid. This improves the production capacity, and the purpose of increasing production and oil was met. It also provides a necessary guarantee for improving the overall development of the well group. The connectivity of thinand-poor layers of selected wells is improved, which increases the recovery degree of small layers of connected wells. For the water injection well, the injection capacity is greatly improved. The water absorption of thin-andpoor layers is improved, and the degree of water drive control is also improved.

\section{References}

1. Lin Fazhi. Application of new fracturing oil displacement technology in three types of reservoirs $[\mathrm{J}]$. Chemical engineering and equipment, 2019 (1): $139-140$

2. Xu Jianjun, Huang Lida, Yan Limei, Yi Na. Insulator Self-Explosion Defect Detection Based on Hierarchical Multi-Task Deep Learning[J]. Transactions of China Electrotechnical Society, 2021,36(07):1407-1415.

3. Na Yi,Jianjun Xu,Limei Yan,Lin Huang. Task Optimization and Scheduling of Distributed Cyberphysical System Based on Improved Ant Colony Algorithm. Future Generation Computer Systems, 109(Aug. 2020), 134-148.

4. Jing Han, Xi Wang, Jianjun Xu, Na Yi. Seyed Saman Ashraf Talesh. Thermodynamic analysis and optimization of an innovative geothermal-based organic Rankine cycle using zeotropic mixtures for power and hydrogen production. International Journal of Hydrogen Energy, 45(2020) 8282-8299. 
5. Yang Zhao, Jianjun Xu, Jingchun Wu. A New Method for Bad Data Identification of Oilfield Power System Based on Enhanced Gravitational SearchFuzzy C-Means Algorithm. IEEE Transactions on Industrial Informatics. VOL. 15, NO. 11, NOVEMBER 2019 5963-5970

6. $\mathrm{Xu}$ jianjun, Deng Fanliang, Zhang Xiaolei, et.al., Application of Distributed power Grid-Connection based on improved GA-GPC algoritthm. Journal of Northeast Petroleum University Vol.44, No.4,2020:105-112 